\title{
Giso Deussen, 65, Professor i.R.
}

Im Herbst 2005 hat Giso Deussen seine Tätigkeit als Professor für Medienpolitik und Medienethik an der Fachhochschule Bonn-Rhein-Sieg in Sankt Augustin beendet. Am 5. August war er 65 Jahre alt geworden. Fast 20 Jahre seines Berufslebens hat er in enger Verbindung mit "Communicatio Socialis" (ComSoc) verbracht, konkret: Er hat unserer Zeitschrift einen Teil seiner Arbeitskraft geschenkt. Von 1976 bis 1988 war er Mitglied des Redaktion genannten Fähnleins von nicht einmal sieben Aufrechten, die unter der organisatorischen Leitung von Josef Hosse $(† 1982)$ und Franz-Josef Eilers die redaktionellen Lasten trug. Von 1989 bis 2002 gehörte er - als einer der aktivsten - dem Redaktionsbeirat an. ComSoc hat ihm viel zu verdanken, nicht nur Ideen, guten Rat und praktische Mitarbeit, sondern auch eine Fülle von Beiträgen. Allein die Register der ersten 30 Jahrgänge (1968-1997) weisen ihn siebenundsiebzigmal als Autor von Aufsätzen, Berichten und Rezensionen aus.

Deussen, am 5. August 1940 als Sohn einer Buchhändlersfamilie in Mönchengladbach geboren, ist ein gründlich Studierter. 1966 schloß er die Theologie mit dem Staatsexamen ab. Die Chance, weiter studieren zu können, nutzte er, indem er ein Ergänzungsstudium (Soziologie, Volkswirtschaft, Publizistik) an der Universität Münster betrieb und 1971 mit einer teils theologischen, teils publizistikwissenschaftlichen Dissertation beendete. Die hat es in sich: „Ethik der Massenkommunikation bei Papst Paul VI.", 1973 bei Schöningh als Buch erschienen, hat sich als Standardwerk zur kirchenamtlichen Medienethik bewährt, nicht nur für die Zeit Pauls VI. (1963-1978), sondern auch - durch ein sorgfältig angelegtes erstes Überblickskapitel - zurückgreifend bis zu Gregor XVI. (18301846), der uns das für Presse und Öffentliche Meinung vernichtende Rundschreiben „Mirari vos“ (1832) hinterlassen hat.

Giso Deussens Berufsweg entwickelte sich als eine vielseitige Publizistenkarriere. Das Journalistenhandwerk erlernte er 1972-1974 bei der „Aachener Volkszeitung“. Danach baute er die Medienarbeit der KonradAdenauer-Stiftung auf, deren Öffentlichkeitsarbeit er von 1974 bis 1983 leitete. Zwischendurch lernte er als freier Mitarbeiter beim Fernsehen der Deutschen Welle, wie man Fernsehfilme macht. 1984 wurde er als Sprecher der Intendanz zum Norddeutschen Rundfunk geholt, 1986 zum RIAS Berlin, wo er als Medienreferent arbeitete und als Leiter der Intendanz dem Intenidanten zugeordnet war. Beim Deutschlandradio Berlin, das nach der Wende aus dem RIAS hervorging, war er von 1994 bis 1996 als Redakteur in der Abteilung Kultur tätig. 
Der letzte Abschnitt seines Berufsweges führte ihn, der an der Freien Universität Berlin Erfahrungen als Lehrbeauftragter gesammelt hatte, an die Fachhochschule Rhein-Sieg, wo er zunächst an der Konzeption eines Studienganges Technik-Journalismus/Technik-PR arbeitete, ab 1998 die einschlägige Professur vertrat und schließlich am 23. Juli 1999 zum Professor für Medienpolitik und Medienethik berufen wurde.

Giso Deussen hat sich, wie man es heute so sagt, auf allen seinen Arbeitsplätzen voll "eingebracht" - vor allem aber hat er sein Wissen und Können publizistisch und lehrend ausgebracht. „Communicatio Socialis“ hat dankbar daran partizipiert und hofft, dies auch weiterhin tun zu dürfen. 